\title{
Factors associated with macrosomia, hypoglycaemia and low Apgar score among Fijian women with gestational diabetes mellitus
}

Falahola Fuka ${ }^{1 \dagger}$, Uchechukwu L. Osuagwu ${ }^{2^{*}}$ (D) Kingsley Agho ${ }^{3,4}$, Rajat Gyaneshwar ${ }^{5+}$, Swaran Naidu ${ }^{5 \dagger}$, James Fong ${ }^{6+}$ and David Simmons ${ }^{2}$

\begin{abstract}
Background: Gestational diabetes mellitus (GDM) in Fiji is a serious public health issue. However, there are no recent studies on GDM among pregnant women in Fiji. The aim of this study was to examine prevalence of, and sociodemographic factors associated with adverse neonatal outcomes among Fijian women with GDM.

Methods: We used cross-sectional data of 255 pregnant women with GDM who gave birth to singleton infants at Colonial War Memorial Hospital (CWMH) in Suva city. Women underwent testing for GDM during antenatal clinic visits and were diagnosed using modified International Association of Diabetes and Pregnancy Study Groups (IADPSG) criteria. Multivariable logistic regression analysis was used to investigate factors associated with neonatal outcomes.

Results: Women with a previous baby weighing $>4 \mathrm{~kg}$ were 6.08 times more likely to experience neonatal macrosomia (Adjusted odds ratio $(A O R)=6.08 ; 95 \% \mathrm{Cl}: 2.46,15.01)$. Compared to unmarried women, the odds of macrosomia among married women reduced by $71 \%(\mathrm{AOR}=0.29 ; 95 \% \mathrm{Cl}: 0.11,0.77)$. Compared with delivery before 38 weeks of gestation, the infants of women who delivered between 38 and 41 weeks of gestation were 62 and $86 \%$ less likely to experience neonatal hypoglycaemia and Apgar score $<7$ at 5 mins, respectively. The offspring of women who were overweight and obese had higher odds of neonatal hypoglycaemia. Late booking in gestation ( $\geq 28$ weeks) was significantly associated with Apgar score $<7$ at 5 min (AOR $=7.87 ; 95 \% C l: 1.11,55.75)$. Maternal pre-eclampsia/ pregnancy induced hypertension was another factor associated with low Apgar score in infants.
\end{abstract}

Conclusions: The study found high rates of adverse neonatal outcomes among off springs of Fijian women with GDM and showed that interventions targeting pregnant women who are overweight, had a previous baby weighing $>4 \mathrm{~kg}$, had pre-eclampsia, delivered before 38 weeks of gestation, and those who booked later than 13 weeks in gestation, are needed to improve pregnancy outcomes.

Keywords: Gestational diabetes mellitus (GDM), Pregnancy, Fiji, Pacific people, Hypoglycaemia, Macrosomia, Apgar score, Diabetes

\footnotetext{
* Correspondence: l.osuagwu@westernsydney.edu.au

${ }^{\dagger}$ Fuka Falahola, Gyaneshwar Rajat, Naidu Swaran and Fong James

contributed equally to this work.

2Diabetes, Obesity and Metabolism Translational Research Unit (DOMTRU),

School of Medicine, Western Sydney University, Campbelltown 2560, NSW,

Australia

Full list of author information is available at the end of the article
}

(c) The Author(s). 2020 Open Access This article is distributed under the terms of the Creative Commons Attribution 4.0 International License (http://creativecommons.org/licenses/by/4.0/), which permits unrestricted use, distribution, and reproduction in any medium, provided you give appropriate credit to the original author(s) and the source, provide a link to the Creative Commons license, and indicate if changes were made. The Creative Commons Public Domain Dedication waiver (http://creativecommons.org/publicdomain/zero/1.0/) applies to the data made available in this article, unless otherwise stated. 


\section{Introduction}

Gestational diabetes mellitus (GDM) is any degree of glucose intolerance that occurs or is diagnosed for the first time during pregnancy [1]. Women with GDM are at high risk of pregnancy complications, including infant macrosomia, neonatal hypoglycaemia, low Apgar score and caesarean delivery [2], have more than a 7-fold increased risk of developing type 2 diabetes 5 to 10 years after delivery [3], and the risk is even higher in obese women with GDM [4]. Children born to mothers with GDM are more likely to develop impaired glucose tolerance later in life, [5] and early detection and appropriate therapy may prevent these complications $[6,7]$.

Globally, it is estimated that GDM affects between 1 and $36 \%$ of pregnancies, depending on the population studied and the diagnostic tests used [2]. Among Pacific people, previous studies conducted in 2008 reported that about $20 \%$ of pregnancies are complicated by GDM [8] but lower rates have been documented among European women living in Auckland who delivered between 1994 and 1995 [9], and White-skinned women in Hawaii, who delivered between 2010 and 2011 [10], compared with Pacific Island women. Lower rates of GDM were reported among Pacific Islands women living in Australia (6.3\%) [11] and in the US (8.3\%) [12], between 2010 and 2011 using the Australasian Diabetes in Pregnancy Society (ADIPS) [1] and the American Diabetes Association (ADA) diagnostic criteria [12]. Independent of maternal body weight, age, parity and education, women particularly those from Pacific countries who were born in their home countries were more likely to have GDM than their counterparts who were born in foreign countries [12]. The authors suggested that the varying degrees of access to medical care, especially recent immigrants who may be less likely to undergo screening for GDM, coupled with other environmental factors in migrant populations may interact with genetic susceptibility to influence the risk of GDM [12].

Fiji has high and increasing rates of obesity and type 2 diabetes among non-pregnant individuals [13] suggesting a high prevalence of gestational diabetes mellitus (GDM), and associated adverse pregnancy outcomes. Maternal obesity and type 2 diabetes were additive for increased risk of GDM [14]. However, there is no up-to-date evidence on the prevalence of, and outcomes from, pregnancies complicated by GDM in Fiji, and a meta-analysis failed to find reliable data on GDM in Pacific Island countries [15]. Prior epidemiological studies from Fiji were either conducted more than three decades ago (1983 [16] and 1990) [17], and/or used diagnostic criteria for GDM (O'Sullivan and Mahan 1964 [17] and WHO 1980 [16]) that are no longer in use. Gyaneshwar and Ram [17] found a higher prevalence of GDM among Fijians of Indian Descent (FIDs) compared with ITaukei Fijians (5\% vs $0.6 \%$ ) and the rate was higher among women who had higher BMI [17]. Zimmet et al. [16] found rural-urban differences in prevalence of diabetes in a Melanesian population with greater differences among women, but no difference was found between rural-urban dwellers among the Indian population. Since these studies (1989-2018), the rates of obesity and diabetes among Pacific Island countries [18] including Fiji [13] have more than doubled, and the criteria for GDM diagnosis in the previous studies were not designed to identify women at risk of adverse perinatal outcomes but to identify those at high risk of subsequently developing type 2 diabetes [19].

In the Colonial War Memorial Hospital (CWMH) Fiji, GDM was previously diagnosed using the ADIPS criteria which consisted of a $75 \mathrm{~g}$ glucose load with a fasting blood glucose $\geq 5.5 \mathrm{mmol} / \mathrm{l}$ and $2 \mathrm{~h} \geq 8.0 \mathrm{mmol} / \mathrm{l}$ and only pregnant women with known risk factors for GDM such as previous GDM and previous big babies, were tested for GDM. In 2013, the hospital commenced a 2-step process of universal testing for GDM, using the modified International Association of Diabetes and Pregnancy Study Groups (IADPSG) criteria described in Fig. 1. Adoption of these criteria followed the findings of the landmark HAPO observational study in 2008 which reported significant relationship between maternal glycaemic levels and pregnancy outcomes [20]. Implementation of the modified (IADPSG) criteria was expected to not only increase the prevalence of GDM, but also to identify the population at higher risk of adverse pregnancy outcomes and who may benefit from targeted interventions to improve pregnancy outcomes [21].

Fijians are genetically different from other populations [22] and along with other Pacific Island nations make up eight of the world's 10 most obese countries [23]. Pacific Islander women are heavier during pregnancy, have higher rates of macrosomia, higher incidence of abnormal glucose tolerance test results post-partum [17], and hence a higher risk of future development of type 2 diabetes mellitus compared to other ethnic groups [24].

This study was conducted to provide recent evidence on the prevalence of, and socio-demographic factors associated with, adverse neonatal outcomes among women with GDM in Fiji. The findings of this study are important to inform local policy and should enable public health researchers to target a sub-population of women with GDM for future interventions and allocation of local resources to areas with high need. The study is also likely to inform practice in rural/remote areas in Fiji and those with significant Melanesian and Polynesian populations (e.g. New Zealand and Australia).

\section{Subjects and methods}

\section{Setting}

Fiji is an island nation in the south-west Pacific Ocean, located between Vanuatu and Tonga. As at 2011, the 


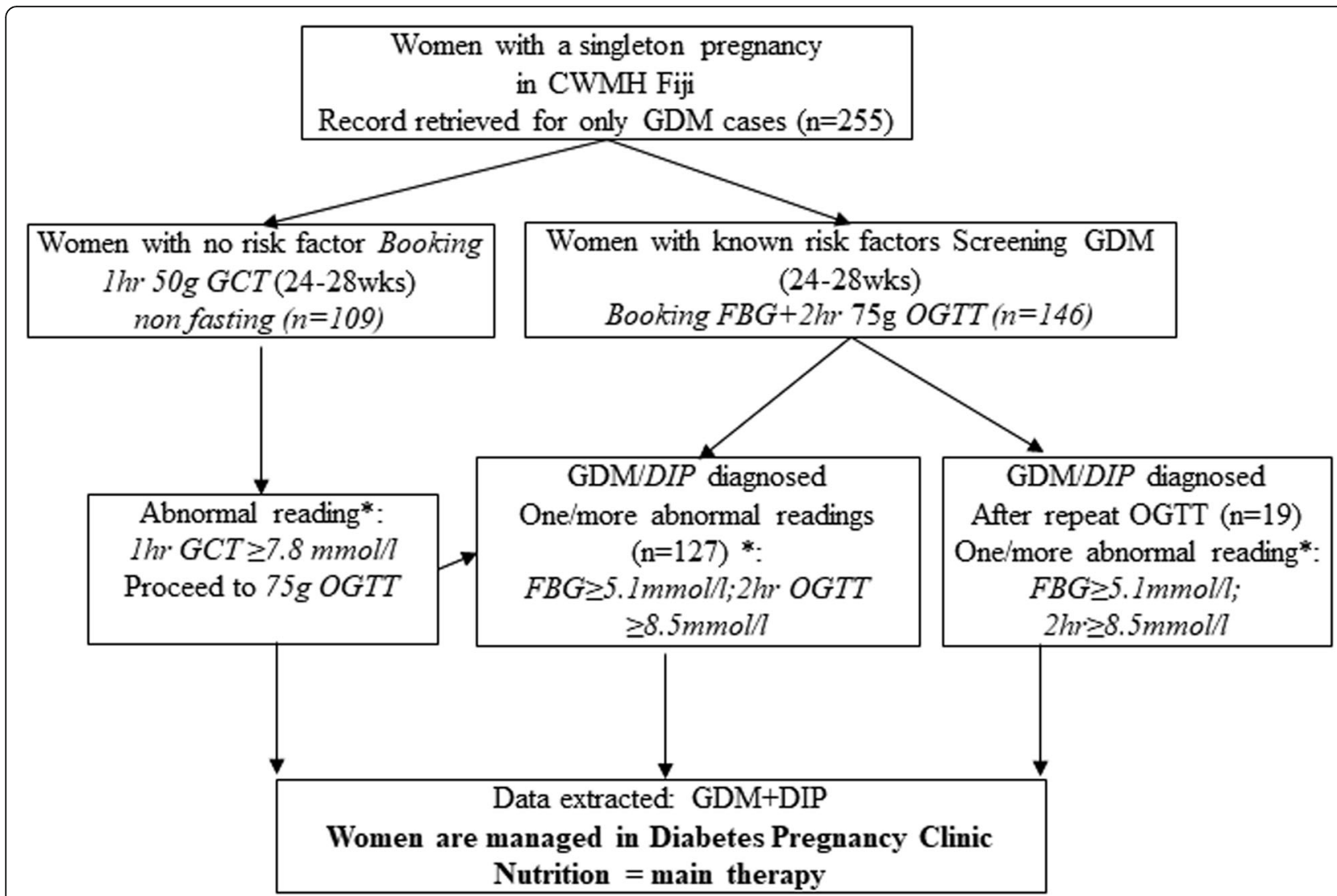

Fig. 1 Flow chart for gestational diabetes mellitus (GDM) testing among pregnant women in an urban Fiji hospital. All pregnant women are routinely tested for GDM using a two-step process consisting of the 1-h glucose challenge test (GCT) at 24-28 weeks including a non-fasting $50 \mathrm{~g}$ glucose load and if GCT was $\geq 7.8 \mathrm{mmol} / \mathrm{l}$, a $2-\mathrm{h} 75 \mathrm{~g}$ oral glucose tolerance test (OGTT) was then performed. One abnormal value is sufficient for diagnosis. The women with any known risk factor for GDM including age $\geq 30$ years, strong family history of diabetes, past history of GDM, previous macrosomic baby and high maternal pre-pregnancy BMI $\geq 30 \mathrm{~kg} / \mathrm{m}^{2}$, proceed to OGT at initial testing. Those who are at high risk for GDM (i.e. women with two or more of the risk factors present at booking) proceed directly to a $2-\mathrm{h} 75 \mathrm{~g} \mathrm{OGTT}$ at the time of their booking with the antenatal clinic. If the early testing with OGTT was normal (fasting $<5.1 \mathrm{mmol} / \mathrm{L}, 2 \mathrm{~h}<8.5 \mathrm{mmol} / \mathrm{L}$ ), the high-risk women underwent another 75-g OGTT at 24-28 weeks' gestation

country has a total population of approximately 884,887 (50.7\% men, $49.3 \%$ women) which is comprised of about 57\% Indigenous Fijians (iTaukei), 37\% FIDs, and 6\% others (including other Pacific people, Chinese and those of European descent). Indigenous Fijians are predominantly of Melanesian extraction, with some Polynesian admixture. About 56\% of Fiji's population resides in urban areas, with the Suva region being the most heavily populated [25]. Colonial War Memorial Hospital (CWMH) in Suva is Fiji's largest and oldest hospital, and the national referral hospital for Fiji with services that are accessed by other Pacific Island countries [26].

\section{Data sources}

Data for 255 women with GDM who gave birth to singleton infants at CWMH in Suva between June 2013 and May 2014, were retrieved from the Diabetes in pregnancy registry; the timeframe 2013-2014 was chosen because it was when the modified IADPSG [27] criteria for
GDM diagnosis were introduced in the hospital. In our analysis, women with pre-existing diabetes i.e. those with known type 1 and type 2 diabetes, were excluded (Fig. 1).

\section{Sample size}

The required sample size for this study was determined using a single population proportion formula. An earlier study reported in 1983 that the prevalence of GDM in Fiji was $22.7 \%$ [16]. This present study assumed the differences in the prevalence of GDM between urban and rural Fijians ranged between 5 and 7\% [16], at $80 \%$ power and $5 \%$ significance level. This gives a sample of 251 women with GDM. Taking into account a dropout rate of about $2 \%$, also based on earlier research [16], a total sample of approximately 255 participants was required. This sample size was sufficient to detect any statistical differences in examining factors associated with GDM among Fijian women. 


\section{Outcome variables}

To determine the outcome variables, we conducted preliminary analysis using frequency distribution for all the neonatal outcomes (see dotted vertical line in Fig. 2) and only those with proportions $>10 \%$ were retained as final outcome variables. This was done to avoid the loss in precision of estimates with wide confidence intervals [28]. The three neonatal outcome variables that were retained in the analysis included: neonatal hypoglycaemia (which was defined as neonatal glucose $\leq 1.6 \mathrm{mmol} / \mathrm{l}$ during the first $24 \mathrm{~h}$ after birth [29]), macrosomia (baby weighing $>4$ $\mathrm{kg}$ ) [20] and Apgar score $<7$ after $5 \mathrm{~min}$. The outcome variables were coded as binary, ' 1 ' for the presence and ' 0 ' for absence. In our analysis, we combined data for those with GDM and DIP due to low count of women with DIP.

\section{Potential cofounding factors}

The choice of potential cofounding factors was based on previous studies [30-32] and included socio-demographic factors (age, ethnicity, marital status, parity, level of education); maternal factors such as body mass index (BMI) calculated at the first prenatal visit using WHO criteria as: underweight $\left(<18.5 \mathrm{~kg} / \mathrm{m}^{2}\right)$, normal $\left(18.5-24.9 \mathrm{~kg} / \mathrm{m}^{2}\right)$, and overweight (from 25 to $29.9 \mathrm{~kg} / \mathrm{m}^{2}$ ), class 1 obesity $\left(30-34.9 \mathrm{~kg} / \mathrm{m}^{2}\right)$ and class $2 / 3$ obesity $\geq 35 \mathrm{~kg} / \mathrm{m}^{2}$ [33], positive family history of diabetes, past history of GDM, baby weighing $>4 \mathrm{~kg}$, stillbirth and neonatal death (which were simply recorded as present or absent); antenatal factors (gestational age at booking, gestational age at diagnosis and gestational age at delivery); and maternal complications such as preeclampsia (defined as hypertension that is onset from at least 20 weeks of pregnancy and accompanied by proteinuria), polyhydramnios, trauma, endometritis and wound infection and mode of delivery (caesarean section and vaginal delivery). Gestational age at delivery was classified into $<37$ weeks and $\geq 37$ weeks. In the regression analysis, BMI was further collapsed into three categories normal, overweight and obese due to low count of underweight, class 2 and class 3 obese women, and levels of education were classified into non-tertiary (no education, primary, secondary) and tertiary (university and polytechnic).

\section{Statistical analysis}

Analyses involved frequency tabulations of all confounding factors in the study population. This was followed by cross tabulation to determine the prevalence of all potential confounding factors. Univariate logistic regression and multivariable logistic regression were performed to determine factors associated with the three key neonatal outcomes of macrosomia, neonatal hypoglycaemia and low Apgar score among offspring of women with GDM. The odds ratios with 95\% confidence intervals were calculated to assess the adjusted odds of the independent variables. All analyses were carried out using STATA/MP version 14 (Stata Corp, College Station, TX, USA).

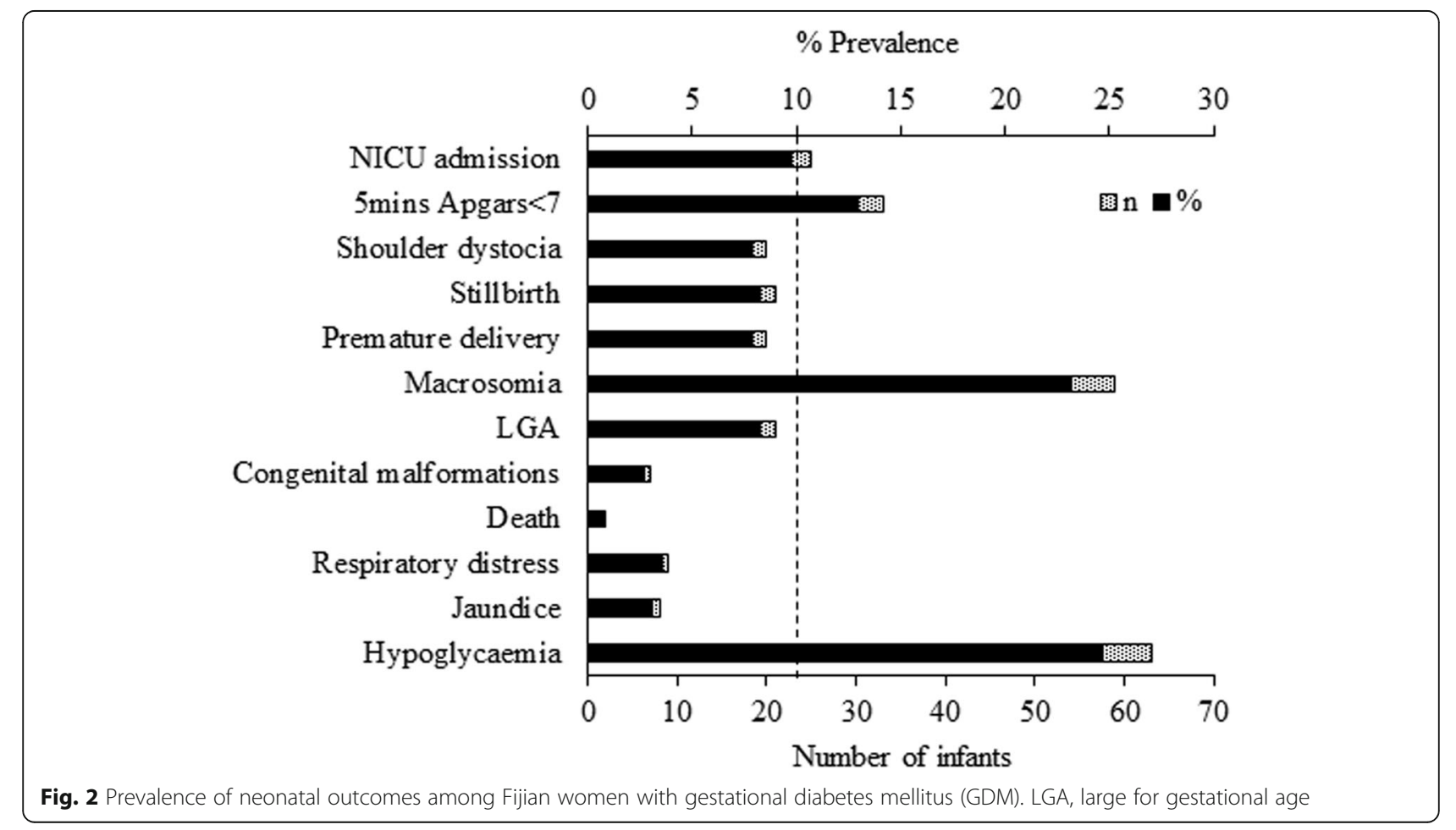




\section{Ethics}

The study used existing datasets that are available from patients' records, and all identifier information was removed prior to analysis. The study was approved by the Ethics Committee of the College of Medical Nursing and Health Sciences of the Fiji National University and by the Fiji National Health Research Ethics Review Committees (ref \#: 2015.48.CEN).

\section{Results}

\section{Characteristics of Fijian women with GDM}

The majority were married $(88.2 \%)$ women who were aged between 26 and 35 years $(62.8 \%)$ and about onethird had tertiary education (37.2\%). The sample had almost equal proportion of Itaukei Fijians and FIDs (49.4\% vs $42.0 \%$ ), the two main ethnic groups in Fiji. Table 1 shows the characteristics of women with GDM in CMWH Fiji. About one-half of mothers booked between 14 and 27 weeks of gestation. A hundred and seventythree women $(67.8 \%)$ had vaginal delivery (majority were non-assisted/normal vaginal deliveries $(n=165,64.7 \%)$ ) and $32.2 \%$ delivered by caesarean section. As indicated in Fig. 2, about $24.7 \%$ of the women with GDM had hypoglycaemic infants, $23.1 \%$ had macrosomic infants, and $12.9 \%$ had infants with Apgar scores $<7$ at $5 \mathrm{~min}$. Shoulder dystocia, stillbirth, premature delivery, large for gestational age (LGA) babies and NICU admissions were other serious adverse neonatal outcomes observed among Fijian women with GDM with prevalence $<10 \%$, each.

\section{Factors associated with macrosomia among Fijian women} with GDM

Table 2 shows the prevalence, univariate and multivariable regression analysis of factors associated with neonatal macrosomia. As indicated in the table, univariate analysis indicated that race or ethnicity, marital status, previous baby weighing $>4 \mathrm{~kg}$, gestational age at booking, gestational age at GDM diagnosis and gestational age at delivery were significantly associated with neonatal macrosomia. After adjusting for potential confounding factors, our results revealed that marital status (married) and having a previous baby weighing $>4 \mathrm{~kg}$ were significantly associated with neonatal macrosomia.

\section{Factors associated with neonatal hypoglycaemia among Fijian women with GDM}

The prevalence, univariate and multivariable regression analysis of factors associated with neonatal hypoglycaemia are presented in Table 3. From the table, it can be seen from the univariate analysis that maternal BMI and gestational age at delivery were significantly associated with neonatal hypoglycaemia. After adjusting for potential confounding factors, our results revealed that gestational age at delivery (<37 weeks of gestation) and maternal BMI (overweight, BMI of $25-29.9 \mathrm{~kg} / \mathrm{m}^{2}$ ) were significantly associated with neonatal hypoglycaemia.

\section{Prevalence and factors associated with neonatal low Apgar Score $<7$ at 5 min}

Table 4 shows the prevalence, univariate and multivariable regression analysis of factors associated with neonatal Apgar score $<7$ at $5 \mathrm{~min}$. As indicated in the table, univariate analysis indicated that gestational age at delivery was significantly associated with neonatal low Apgar score. After adjusting for potential confounding factors, our results revealed that gestational age at booking $(\geq 28$ weeks) and at delivery ( $<37$ weeks), and maternal preeclampsia, were significantly associated with neonatal low Apgar score among Fijian women with GDM.

\section{Discussion}

In the last 30 years, this is the first study to provide evidence of GDM and associated outcomes among Fijian women. We found high rates of adverse neonatal outcomes in this population which far exceeded the rates for the background population and in some cases almost doubled the rate [34] and they were far above the rates among other Pacific Islander women [32, 35, 36]. The key factors associated with such high rates of neonatal outcomes among Fijian women with GDM included previous baby weighing $>4 \mathrm{~kg}$, maternal BMI (overweight/ obese), gestational age at booking ( $\geq 28$ weeks) and gestational age at delivery $(<37$ weeks), and maternal preeclampsia or pregnancy-induced hypertension. Also of importance in this population were obesity, ethnicity, and a family history of diabetes, which interacted with other variables to influence the odds of neonatal outcomes in this study.

The proportion of women who had macrosomic babies $(23 \%)$ in this study (see Fig. 2) was comparable to the global report in GDM (15-45\%) but the rates almost doubled the reported rate among other Pacific Islands women with [32, 35-38] and without GDM (12\%) [39]. This may be related to the high rate of obesity in this cohort (where $68 \%$ of the women were obese, Table 1) - a reflection of the obesity epidemic in the country. The finding of a significant association between macrosomia and previous baby weighing $>4 \mathrm{~kg}$ was consistent with previous reports from observational $[40,41]$ and cohort studies [42] that showed a strong relationship between macrosomia and a previous history of macrosomia. In the observational study, the authors found that up to $78 \%$ of the women who reported a previous history of macrosomia had repeat macrosomia [41]. It is known that all macrosomic infants represent a high-risk group, regardless of maternal diabetes status [43, 44]. Clausen et al. in 2005 [45] and Schaefer-Graf in 2003 [46] 
Table 1 Maternal Characteristics of Fijian women with GDM

\begin{tabular}{|c|c|}
\hline Study characteristics & $n=255$ \\
\hline \multicolumn{2}{|l|}{ Maternal sociodemographic characteristics } \\
\hline Age (years) & $30.7 \pm 5.5$ \\
\hline $18-25$ & 46 \\
\hline $26-35$ & 160 \\
\hline$\geq 36$ & 49 \\
\hline \multicolumn{2}{|l|}{ Racelethnicity } \\
\hline Others $^{\S}$ & 22 \\
\hline Itaukei Fijians & 126 \\
\hline FIDs & 107 \\
\hline \multicolumn{2}{|l|}{ Educational level ${ }^{\ddagger}$} \\
\hline Non-tertiary (primary/secondary) & 157 \\
\hline Tertiary (university/polytechnic) & 93 \\
\hline \multicolumn{2}{|l|}{ Marital status } \\
\hline Not married & 30 \\
\hline Married & 225 \\
\hline \multicolumn{2}{|l|}{ Gravidity (number of pregnancies) } \\
\hline Primigravid (first pregnancy) & 34 \\
\hline Multiparous (2/more children) & 177 \\
\hline Grand multiparous ( $\geq 5$ children) & 44 \\
\hline \multicolumn{2}{|l|}{ Maternal risk factors (yes, no) } \\
\hline \multicolumn{2}{|l|}{ Family history of diabetes } \\
\hline Yes & 128 \\
\hline No & 127 \\
\hline \multicolumn{2}{|l|}{ Previous history of GDM } \\
\hline Yes & 11 \\
\hline No & 244 \\
\hline \multicolumn{2}{|l|}{ Previous baby $>4 \mathrm{~kg}$} \\
\hline Yes & 55 \\
\hline No & 200 \\
\hline \multicolumn{2}{|l|}{ Previous stillbirth } \\
\hline Yes & 11 \\
\hline No & 244 \\
\hline \multicolumn{2}{|l|}{ Previous neonatal death } \\
\hline Yes & 10 \\
\hline No & 245 \\
\hline Maternal BMI $\left(\mathrm{kg} / \mathrm{m}^{2}\right)^{\neq}$ & $33.2 \pm 7.5$ \\
\hline Underweight/normal $(<25)$ & 35 \\
\hline Overweight (25-29.9) & 40 \\
\hline Obese (classes $1-3, \geq 30.0$ ) & 160 \\
\hline
\end{tabular}

Antenatal factors (weeks)

Gestational age at booking

1st trimester (0-13)

2nd trimester (14-27)

3rd trimester $(\geq 28)$

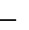

62.8

19.2

8.6

49.4

42.0

62.8

37.2

11.8

88.2

13.3

69.4

17.3

50.2

49.8

4.3

95.7

21.6

78.4

4.3

95.7

3.9

96.1

14.9

17.0

68.1

$18.9 \pm 7.5$

79

134

42
Table 1 Maternal Characteristics of Fijian women with GDM (Continued)

\begin{tabular}{|c|c|c|}
\hline Study characteristics & $n=255$ & $\%$ \\
\hline Gestational age at GDM diagnosis & $25.6 \pm 7.8$ & \\
\hline 1st trimester (0-13) & 26 & 10.2 \\
\hline 2nd trimester (14-27) & 111 & 43.5 \\
\hline 3rd trimester $(\geq 27)$ & 118 & 46.3 \\
\hline Gestational age at delivery & $38.3 \pm 2.2$ & \\
\hline$<37$ & 44 & 17.2 \\
\hline $37-41$ & 211 & 82.8 \\
\hline \multicolumn{3}{|l|}{ Maternal post-pregnancy factors } \\
\hline \multicolumn{3}{|l|}{ Mode of delivery } \\
\hline Vaginal delivery & 173 & 67.8 \\
\hline Caesarean section & 82 & 32.2 \\
\hline \multicolumn{3}{|l|}{ Induced labour } \\
\hline Yes & 98 & 38.4 \\
\hline No & 157 & 61.6 \\
\hline \multicolumn{3}{|l|}{ Preeclampsia } \\
\hline Yes & 48 & 18.8 \\
\hline No & 207 & 81.2 \\
\hline \multicolumn{3}{|l|}{ Polyhydramnios } \\
\hline Yes & 2 & 0.8 \\
\hline No & 253 & 99.2 \\
\hline \multicolumn{3}{|l|}{ Infection $^{*}$} \\
\hline Yes & 3 & 1.2 \\
\hline No & 251 & 98.8 \\
\hline
\end{tabular}

$B M I$ body mass index, GDM gestational diabetes mellitus, FIDs Fijians of Indian Descent

${ }^{5}$ others means part-Europeans, Chinese, and other Pacific Islanders

${ }^{\ddagger}$ there were few missing data, so the denominator was less than 255

reported similar data. They found that high $\mathrm{HbA}_{1 \mathrm{c}}$ at admission and maternal BMI were independently associated with serious adverse fetal outcomes including perinatal mortality and/or major congenital malformations [45], and maternal BMI and previous macrosomic baby appear to have the strongest influence on fetal growth in the late second and early third trimester; maternal glycaemia predominated in the third trimester [46]. It was suggested that the process leading to macrosomia in infants starts in the second trimester of pregnancy [47], however, other studies have found a relationship of some factors in 1st trimester that correlated with macrosomia $[48,49]$. These findings suggest the need for early identification of the women with GDM (particularly those at high risk) for interventions that could potentially reduce the rate of macrosomia and other outcomes associated with macrosomia such as shoulder dystocia and caesarean section deliveries which were also higher in this study compared to the background population [50]. 
Table 2 Prevalence, unadjusted (OR) and odds ratios (AOR) for neonatal macrosomia among Fijian women with GDM, 2013-2014

\begin{tabular}{|c|c|c|c|c|c|}
\hline Variables & Prevalence of macrosomia (\%) & OR & $95 \% \mathrm{Cl}$ & $\mathrm{AOR}$ & $95 \% \mathrm{Cl}$ \\
\hline \multicolumn{6}{|l|}{ Maternal sociodemographic characteristic } \\
\hline \multicolumn{6}{|l|}{ Age (years) } \\
\hline $18-25$ & 17.4 & 1.00 & & 1.00 & \\
\hline $26-35$ & 25.0 & 1.58 & $0.68,3.68$ & 1.27 & $0.44,3.72$ \\
\hline$\geq 36+$ & 22.5 & 1.38 & $0.50,3.80$ & 0.70 & $0.17,2.89$ \\
\hline \multicolumn{6}{|l|}{ Race/ethnicity } \\
\hline Others $^{\S}$ & 31.8 & 1.00 & & 1.00 & \\
\hline Itaukei Fijians & 31.0 & 0.96 & & 0.95 & $0.29,3.12$ \\
\hline FIDs & 12.2 & 0.30 & $0.10,0.80^{*}$ & 0.50 & $0.12,2.02$ \\
\hline \multicolumn{6}{|l|}{ Educational level } \\
\hline Non-tertiary (primary/secondary) & 24.2 & 1.00 & & 1.00 & \\
\hline Tertiary (university/polytechnic) & 21.5 & 0.86 & $0.46,1.59$ & 0.64 & $0.29,1.42$ \\
\hline \multicolumn{6}{|l|}{ Marital status } \\
\hline Not married & 40.0 & 1.00 & & 1.00 & \\
\hline Married & 20.9 & 0.40 & $0.16,0.88^{*}$ & 0.29 & $0.11,0.77^{*}$ \\
\hline \multicolumn{6}{|l|}{ Gravidity (number of pregnancies) } \\
\hline Primigravid (first pregnancy) & 11.8 & 1.00 & & 1.00 & \\
\hline Multiparous (2/more children) & 23.7 & 2.33 & $0.78,7.00$ & 1.17 & $0.30,4.63$ \\
\hline Grand multiparous ( $\geq 5$ children) & 29.6 & 3.15 & $0.92,10.74$ & 0.85 & $0.15,4.69$ \\
\hline \multicolumn{6}{|l|}{ Maternal risk factors (Yes/No) } \\
\hline \multicolumn{6}{|l|}{ Family history of diabetes } \\
\hline No & 28.4 & 1.00 & & 1.00 & \\
\hline Yes & 17.8 & 0.55 & $0.31,1.00$ & 0.69 & $0.31,1.54$ \\
\hline \multicolumn{6}{|l|}{ Previous history of GDM } \\
\hline No & 23.4 & 1.00 & & 1.00 & \\
\hline Yes & 18.2 & 0.73 & $0.15,3.47$ & 3.68 & $0.58,23.40$ \\
\hline \multicolumn{6}{|l|}{ Previous baby $>4 \mathrm{~kg}$} \\
\hline No & 15.5 & 1.00 & & 1.00 & \\
\hline Yes & 50.9 & 5.65 & $2.94,10.86^{*}$ & 6.08 & $2.46,15.01^{*}$ \\
\hline \multicolumn{6}{|l|}{ Previous stillbirth } \\
\hline No & 23.4 & 1.00 & & 1.00 & \\
\hline Yes & 18.2 & 0.73 & $0.15,3.47$ & 0.51 & $0.07,3.70$ \\
\hline \multicolumn{6}{|l|}{ Previous neonatal death } \\
\hline No & 22.9 & 1.00 & & 1.00 & \\
\hline Yes & 30.0 & 1.45 & $0.36,5.78$ & 2.92 & $0.46,18.72$ \\
\hline \multicolumn{6}{|l|}{ Maternal BMI $\left(\mathrm{kg} / \mathrm{m}^{2}\right)$} \\
\hline Underweight / normal) & 17.1 & 1.00 & & 1.00 & \\
\hline Overweight & 15.0 & 0.85 & $0.25,2.93$ & 0.93 & $0.21,4.12$ \\
\hline Obese (classes 1-3, $\geq 30.0$ ) & 26.3 & 1.72 & $0.67,4.43$ & 1.11 & $0.33,3.71$ \\
\hline \multicolumn{6}{|l|}{ Antenatal factors } \\
\hline \multicolumn{6}{|l|}{ Booking age of gestation (weeks) } \\
\hline 1st trimester (0-13) & 12.7 & 1.00 & & 1.00 & \\
\hline 2nd trimester (14-27) & 26.9 & 2.53 & $1.18,5.45^{*}$ & 1.59 & $0.60,4.25$ \\
\hline 3rd trimester $(\geq 28)$ & 31.0 & 3.09 & $1.22,7.85^{*}$ & 0.67 & $0.18,2.57$ \\
\hline
\end{tabular}


Table 2 Prevalence, unadjusted (OR) and odds ratios (AOR) for neonatal macrosomia among Fijian women with GDM, 2013-2014 (Continued)

\begin{tabular}{|c|c|c|c|c|c|}
\hline Variables & Prevalence of macrosomia (\%) & OR & $95 \% \mathrm{Cl}$ & AOR & $95 \% \mathrm{Cl}$ \\
\hline \multicolumn{6}{|c|}{ Gestational age at GDM diagnosis (weeks) } \\
\hline 1st trimester $(0-13)$ & 3.9 & 1.00 & & 1.00 & \\
\hline 2nd trimester (14-27) & 21.6 & 6.90 & $0.89,53.53$ & 3.44 & $0.34,34.81$ \\
\hline 3rd trimester $(\geq 27)$ & 28.8 & 10.12 & $1.32,77.67^{*}$ & 4.30 & $0.41,45.30$ \\
\hline \multicolumn{6}{|c|}{ Gestational age at delivery (weeks) } \\
\hline$<37$ & 9.1 & 1.00 & & 1.00 & \\
\hline $37-41$ & 26.1 & 3.53 & $1.21,10.31^{*}$ & 2.72 & $0.75,9.86$ \\
\hline \multicolumn{6}{|c|}{ Maternal post-pregnancy factors } \\
\hline \multicolumn{6}{|l|}{ Delivery intervention } \\
\hline \multicolumn{6}{|l|}{ Induced labour } \\
\hline No & 23.3 & 1.00 & & 1.00 & \\
\hline Yes & 23.1 & 0.99 & $0.18,0.50$ & 1.37 & $0.13,14.30$ \\
\hline \multicolumn{6}{|l|}{ Caesarean section } \\
\hline No & 24.3 & 1.00 & & 1.00 & \\
\hline Yes & 20.5 & 0.80 & $0.42,1.54$ & 1.16 & $0.55,3.49$ \\
\hline \multicolumn{6}{|l|}{ Preeclampsia } \\
\hline No & 23.2 & 1.00 & & 1.00 & \\
\hline Yes & 22.9 & 0.98 & $0.47,2.08$ & 1.13 & $0.43,3.02$ \\
\hline
\end{tabular}

${ }^{*}$ Confidence Interval $(\mathrm{Cl})$ that does not include 1.00 , significant

$B M I$ body mass index, GDM gestational diabetes mellitus, FIDs Fijians of Indian Descent

§others means part-Europeans, Chinese, and other Pacific Islanders

Although the prevalence of neonatal hypoglycaemia was higher in this study than in previous studies involving European $(3-4 \%)[35,51]$ and other Pacific Islander $(16.6 \%)$ women with GDM $[32,35]$, the association with maternal BMI was consistent with reports from Brazil [42], Spain [42], Australia [43] and New Zealand [29, 34] among women with GDM. The burden of adult overweight, obesity, and associated non-communicable diseases (NCDs) has been widely acknowledged in at least 17 Pacific Island countries, including Fiji, which have current national NCD plans or strategies in place [52]. The findings of this study suggest the need for a prepregnancy program that incorporates both lifestyle and dietary interventions in addressing the issue of obesity among Fijian women with GDM [53].

Another important finding of this study was the significant reduction in the odds of all three key outcomes particularly for neonatal hypoglycaemia and low Apgar score, among women who delivered at term (38-41 weeks of gestation) compared to those who delivered before 37 weeks of gestation. Similar association between pre-term delivery and hypoglycaemia have been reported not only among women with GDM $[54,55]$ but also among those without GDM [56] and the risk increased with the level of hyperglycaemia [57]. The rate of preterm delivery in this cohort (17\%) was almost double the rate that was reported for the background population (9.9\%) in 2012 [34]. In this study, infants who were delivered at term were less likely to have low Apgar score compared to infants who were delivered preterm. This finding may be related to the fact that fewer women had preterm or caesarean deliveries compared with those who had delivered at term or by vaginal delivery (Table 1). A previous study found that low Apgar scores at $5 \mathrm{~min}$ was more frequent in infants who were delivered preterm or by caesarean section compared with infants who were delivered at term or by vaginal delivery [58].

There were other serious adverse outcomes in this study such as shoulder dystocia, stillbirths, and NICU admissions (Fig. 2) which were also worse in this population compared to other Pacific Islands women with GDM $[11,32,35,36]$. These may reflect the higher burden of the disease [59] as well as the low quality of obstetric care in public hospitals in Fiji. Ensuring that pregnant women with GDM, particularly those at high risk of complications, are capable of self-monitoring their glucose levels by making available home blood glucose meters (which currently is not possible due to lack of affordability) will help improve pregnancy outcomes 
Table 3 Prevalence, unadjusted (OR) and odds ratios (AOR) for neonatal hypoglycaemia among Fijian women with GDM, 2013-2014

\begin{tabular}{|c|c|c|c|c|c|}
\hline Variables & Prevalence of hypoglycaemia (\%) & OR & $95 \% \mathrm{Cl}$ & AOR & $95 \% \mathrm{Cl}$ \\
\hline \multicolumn{6}{|l|}{ Maternal sociodemographic factors } \\
\hline \multicolumn{6}{|l|}{ Age (years) } \\
\hline $18-25$ & 21.7 & 1.00 & & 1.00 & \\
\hline $26-35$ & 22.6 & 1.05 & $0.48,2.33$ & 0.82 & $0.32,2.14$ \\
\hline$\geq 36$ & 34.7 & 1.91 & $0.77,4.77$ & 1.31 & $0.40,4.35$ \\
\hline \multicolumn{6}{|l|}{ Racelethnicity } \\
\hline Others $^{\S}$ & 31.8 & 1.00 & & 1.00 & \\
\hline Itaukei Fijians & 26.2 & 0.76 & $0.29,2.03$ & 0.97 & $0.30,3.13$ \\
\hline FIDs & 21.7 & 0.59 & $0.22,1.63$ & 0.95 & $0.26,3.47$ \\
\hline \multicolumn{6}{|l|}{ Educational level } \\
\hline Non-tertiary (primary/secondary) & 26.9 & 1.00 & & 1.00 & \\
\hline Tertiary (university/polytechnic) & 21.5 & 0.74 & $0.41,1.37$ & 0.76 & $0.37,1.56$ \\
\hline \multicolumn{6}{|l|}{ Marital status } \\
\hline Not married & 27.6 & 1.00 & & 1.00 & \\
\hline Married & 24.4 & 0.85 & $0.36,2.03$ & 0.72 & $0.26,1.97$ \\
\hline \multicolumn{6}{|l|}{ Gravidity (number of pregnancies) } \\
\hline Primigravid (first pregnancy) & 11.8 & 1.00 & & 1.00 & \\
\hline Multiparous (2/more children) & 27.3 & 2.81 & $0.94,8.40$ & 2.42 & $0.67,8.73$ \\
\hline Grand multiparous ( $\geq 5$ children) & 25.0 & 2.50 & $0.72,8.70$ & 1.46 & $0.29,7.42$ \\
\hline \multicolumn{6}{|l|}{ Maternal risk factors (yes, no) } \\
\hline \multicolumn{6}{|l|}{ Family history of diabetes } \\
\hline No & 26.8 & 1.00 & & 1.00 & \\
\hline Yes & 22.8 & 0.81 & $0.46,1.43$ & 0.95 & $0.47,1.95$ \\
\hline \multicolumn{6}{|l|}{ Previous history of GDM } \\
\hline No & 24.3 & 1.00 & & 1.00 & \\
\hline Yes & 36.4 & 1.78 & $0.50,6.30$ & 0.83 & $0.16,4.39$ \\
\hline \multicolumn{6}{|l|}{ Previous baby $>4 \mathrm{~kg}$} \\
\hline No & 22.6 & 1.00 & & 1.00 & \\
\hline Yes & 32.7 & 1.66 & $0.87,3.20$ & 1.19 & $0.51,2.76$ \\
\hline \multicolumn{6}{|l|}{ Previous stillbirth } \\
\hline No & 24.7 & 1.00 & & 1.00 & \\
\hline Yes & 27.3 & 1.14 & $0.29,4.45$ & 1.42 & $0.27,7.45$ \\
\hline \multicolumn{6}{|l|}{ Previous neonatal death } \\
\hline No & 24.2 & 1.00 & & 1.00 & \\
\hline Yes & 40.0 & 2.09 & $0.57,7.66$ & 3.96 & $0.79,19.90$ \\
\hline \multicolumn{6}{|l|}{ Maternal BMI $\left(\mathrm{kg} / \mathrm{m}^{2}\right)$} \\
\hline Underweight/normal $(<25)$ & 8.8 & 1.00 & & 1.00 & \\
\hline Overweight (25-29.9) & 32.5 & 4.98 & $1.28,19.33^{*}$ & 5.49 & $1.01,29.96^{*}$ \\
\hline Obese (classes $1-3, \geq 30.0$ ) & 27.5 & 3.92 & $1.14,13.48^{*}$ & 4.34 & $0.87,21.65$ \\
\hline \multicolumn{6}{|l|}{ Antenatal factors } \\
\hline \multicolumn{6}{|l|}{ Booking age of gestation (weeks) } \\
\hline 1st trimester (0-13) & 24.1 & 1.00 & & 1.00 & \\
\hline 2nd trimester (14-27) & 25.6 & 1.08 & $0.57,2.07$ & 1.72 & $0.68,4.34$ \\
\hline 3rd trimester $(\geq 28)$ & 23.8 & 0.99 & $0.41,2.37$ & 1.09 & $0.30,3.95$ \\
\hline
\end{tabular}


Table 3 Prevalence, unadjusted (OR) and odds ratios (AOR) for neonatal hypoglycaemia among Fijian women with GDM, 2013-2014 (Continued)

\begin{tabular}{|c|c|c|c|c|c|}
\hline Variables & Prevalence of hypoglycaemia (\%) & OR & $95 \% \mathrm{Cl}$ & AOR & $95 \% \mathrm{Cl}$ \\
\hline \multicolumn{6}{|c|}{ Age of gestation at GDM diagnosis (weeks) } \\
\hline 1st trimester (0-13) & 38.5 & 1.00 & & 1.00 & \\
\hline 2nd trimester (14-27) & 21.6 & 0.44 & $0.18,1.10$ & 0.40 & $0.10,1.52$ \\
\hline 3rd trimester $(\geq 27)$ & 24.8 & 0.53 & $0.22,1.29$ & 0.53 & $0.13,2.17$ \\
\hline \multicolumn{6}{|c|}{ Age of gestation at delivery (weeks) } \\
\hline$<37$ & 39.5 & 1.00 & & 1.00 & \\
\hline $37-41$ & 21.8 & 0.43 & $0.21,0.85^{*}$ & 0.38 & $0.17,0.89^{*}$ \\
\hline \multicolumn{6}{|c|}{ Maternal post-pregnancy factors } \\
\hline \multicolumn{6}{|l|}{ Delivery intervention } \\
\hline \multicolumn{6}{|l|}{ Induced labour } \\
\hline No & 23.3 & 1.00 & & 1.00 & \\
\hline Yes & 25.6 & 1.14 & $0.62,2.09$ & 0.52 & $0.06,4.20$ \\
\hline \multicolumn{6}{|l|}{ Caesarean section } \\
\hline No & 21.0 & 1.00 & & 1.00 & \\
\hline Yes & 33.3 & 1.88 & $1.04,3.40$ & 2.86 & $0.15,56.32$ \\
\hline \multicolumn{6}{|l|}{ Preeclampsia } \\
\hline No & 22.8 & 1.00 & & 1.00 & \\
\hline Yes & 33.3 & 1.69 & $0.86,3.35$ & 1.32 & $0.59,3.01$ \\
\hline \multicolumn{6}{|l|}{ Polyhydramnios } \\
\hline No & 24.6 & 1.00 & & 1.00 & \\
\hline Yes & 50.0 & 3.06 & $0.18,49.72$ & 2.32 & $0.11,48.31$ \\
\hline \multicolumn{6}{|l|}{ Endometritis } \\
\hline No & 24.7 & 1.00 & & - & \\
\hline Yes & 50.0 & 3.05 & $0.19,49.5$ & - & - \\
\hline
\end{tabular}

${ }^{*}$ Confidence Interval $(\mathrm{Cl})$ that does not include 1.00 , significant

$B M I$ body mass index, GDM gestational diabetes mellitus, FIDs Fijians of Indian Descent

${ }^{\S}$ others means part-Europeans, Chinese, and other Pacific Islanders

in GDM. Additionally, the high rate of low Apgar scores found in this study indicates the need for regular audit of the diabetes clinic to identify areas of improvement in the quality of care.

Pacific Islands women are known to book late in gestation [9] and this was reflected in our study where more than two-thirds of the women had late booking (booked after 13 weeks of gestation). In a recent randomised RCT, early booking in gestation identified pregnant women who can benefit from early treatment for GDM, to reduce pregnancy complications [60]. In the TOBOGM study, $89 \%$ of untreated women had GDM early in gestation (at both 18 weeks and 24-28 weeks gestation), making the case for early screening in pregnancy [60], however, the decision as to whether to treat or not early in gestation remains controversial. The present study found that early booking in gestation was associated with some reduction in the odds of macrosomia and significant reduction in the odds of low Apgar score by up to $80 \%$ (Table 4). Public health officers need to step up effective targeted strategies to promote early booking in gestation preferably in the first trimester of pregnancy, among women with and without GDM.

The limitations of this study were that: 1 ), the findings cannot be generalized to the entire population of pregnant women with GDM in Fiji because we only considered women with GDM from a single hospital registry in urban Fiji; 2), the study reported outcomes of mothers with GDM without a control group for direct comparison. Future studies should compare the sociodemographic factors associated with adverse outcomes between women with and without GDM; 3), the study did not adequately test the effect of pre-pregnancy BMI and data for gestational weight gain was not captured. However, with the high prevalence of overweight and obesity in this study, it is critical to understand the effect of maternal body mass on neonatal outcomes; 4), although the use of glucose challenge tests for screening those with no risk factors is an acceptable approach [61], the test potentially misses those with fasting hyperglycaemia, thus OGTT was performed in this study; and 5), the study used a cut-off point of $<1.6$ for 
Table 4 Prevalence, unadjusted (OR) and odds ratios (AOR) for lower Apgar scores among Fijian women with GDM, 2013-2014

\begin{tabular}{|c|c|c|c|c|c|}
\hline Variables & Prevalence of low Apgar score (\%) & OR & $95 \% \mathrm{Cl}$ & AOR & $95 \% \mathrm{Cl}$ \\
\hline \multicolumn{6}{|l|}{ Maternal sociodemographic factors } \\
\hline \multicolumn{6}{|l|}{ Age (years) } \\
\hline $18-25$ & 15.2 & 1.00 & & 1.00 & \\
\hline $26-35$ & 13.9 & 0.90 & $0.36,2.27$ & 0.97 & $0.26,3.59$ \\
\hline$\geq 36$ & 8.2 & 0.50 & $0.14,1.82$ & 0.18 & $0.02,1.44$ \\
\hline \multicolumn{6}{|l|}{ Racelethnicity } \\
\hline Others $^{a}$ & 9.1 & 1.00 & & 1.00 & \\
\hline Itaukei Fijians & 11.2 & 1.26 & $0.27,5.98$ & 1.32 & $0.20,8.61$ \\
\hline FIDs & 16.0 & 1.91 & $0.41,8.94$ & 1.60 & $0.21,11.92$ \\
\hline \multicolumn{6}{|l|}{ Educational level } \\
\hline Non-tertiary (primary/secondary) & 16.0 & 1.00 & & 1.00 & \\
\hline Tertiary (university/polytechnic) & 8.7 & 0.50 & $0.22,1.16$ & 0.54 & $0.18,1.62$ \\
\hline \multicolumn{6}{|l|}{ Marital status } \\
\hline Not married & 10.3 & 1.00 & & 1.00 & \\
\hline Married & 13.4 & 1.34 & $0.38,4.70$ & 1.66 & $0.35,7.85$ \\
\hline \multicolumn{6}{|l|}{ Gravidity (number of pregnancies) } \\
\hline Primigravid (first pregnancy) & 11.8 & 1.00 & & 1.00 & \\
\hline Multiparous (2/more children) & 14.3 & 1.25 & $0.41,3.85$ & 2.77 & $0.58,13.29$ \\
\hline Grand multiparous ( $\geq 5$ children) & 9.1 & 0.75 & $0.17,3.24$ & 1.77 & $0.19,16.60$ \\
\hline \multicolumn{6}{|l|}{ Maternal risk factors (yes, no) } \\
\hline \multicolumn{6}{|l|}{ Family history of diabetes } \\
\hline No & 13.4 & 1.00 & & 1.00 & \\
\hline Yes & 12.7 & 0.94 & $0.45,1.96$ & 1.40 & $0.52,3.76$ \\
\hline \multicolumn{6}{|l|}{ Previous baby $>4 \mathrm{~kg}$} \\
\hline No & 13.6 & 1.00 & & 1.00 & \\
\hline Yes & 10.9 & 0.78 & $0.30,1.99$ & 1.64 & $0.45,5.95$ \\
\hline \multicolumn{6}{|l|}{ Previous neonatal death } \\
\hline No & 13.2 & 1.00 & & 1.00 & \\
\hline Yes & 10.0 & 0.73 & $0.09,5.98$ & 1.49 & $0.12,18.50$ \\
\hline \multicolumn{6}{|l|}{ Maternal BMI $\left(\mathrm{kg} / \mathrm{m}^{2}\right)$} \\
\hline Underweight/normal $(<25)$ & 14.7 & 1.00 & & 1.00 & \\
\hline Overweight (25-29.9) & 22.5 & 1.68 & $0.50,5.62$ & 1.58 & $0.37,6.70$ \\
\hline Obese (classes $1-3, \geq 30.0$ ) & 10.7 & 0.69 & $0.24,2.03$ & 0.28 & $0.07,1.16$ \\
\hline \multicolumn{6}{|l|}{ Antenatal factors } \\
\hline \multicolumn{6}{|l|}{ Booking age of gestation (weeks) } \\
\hline 1st trimester (0-13) & 11.4 & 1.00 & & 1.00 & \\
\hline 2nd trimester (14-27) & 12.9 & 1.15 & $0.49,2.72$ & 1.46 & $0.44,4.85$ \\
\hline 3rd trimester $(\geq 28)$ & 16.7 & 1.56 & $0.54,4.53$ & 7.87 & $1.11,55.75^{*}$ \\
\hline \multicolumn{6}{|c|}{ Age of gestation at GDM diagnosis (weeks) } \\
\hline 1st trimester (0-13) & 11.5 & 1.00 & & 1.00 & \\
\hline 2nd trimester (14-27) & 15.5 & 1.40 & $0.38,5.19$ & 1.53 & $0.24,10.01$ \\
\hline 3rd trimester $(\geq 27)$ & 11.1 & 0.96 & $0.25,3.64$ & 0.53 & $0.06,4.56$ \\
\hline \multicolumn{6}{|l|}{ Age of gestation at delivery (weeks) } \\
\hline$<37$ & 27.9 & 1.00 & & 1.00 & \\
\hline
\end{tabular}


Table 4 Prevalence, unadjusted (OR) and odds ratios (AOR) for lower Apgar scores among Fijian women with GDM, 2013-2014 (Continued)

\begin{tabular}{|c|c|c|c|c|c|}
\hline Variables & Prevalence of low Apgar score (\%) & OR & $95 \% \mathrm{Cl}$ & AOR & $95 \% \mathrm{Cl}$ \\
\hline $37-41$ & 10.0 & 0.29 & $0.13,0.64^{*}$ & 0.14 & $0.04,0.46^{*}$ \\
\hline \multicolumn{6}{|c|}{ Maternal post-pregnancy factors } \\
\hline \multicolumn{6}{|c|}{ Delivery intervention } \\
\hline \multicolumn{6}{|c|}{ Induced labour } \\
\hline No & 10.6 & 1.00 & & 1.00 & \\
\hline Yes & 14.3 & 1.41 & $0.62,3.18$ & 0.16 & $0.01,2.52$ \\
\hline \multicolumn{6}{|c|}{ Caesarean section } \\
\hline No & 15.4 & 1.00 & & 1.00 & \\
\hline Yes & 7.7 & 0.46 & $0.18,1.16$ & 2.86 & $0.16,56.32$ \\
\hline \multicolumn{6}{|c|}{ Preeclampsia } \\
\hline No & 11.2 & 1.00 & & 1.00 & \\
\hline Yes & 20.8 & 2.08 & $0.92,4.73$ & 5.57 & $1.73,18.00^{*}$ \\
\hline \multicolumn{6}{|c|}{ Polyhydramnios } \\
\hline No & 12.8 & 1.00 & & 1.00 & \\
\hline Yes & 50.0 & 6.84 & $0.42,112.15$ & 10.51 & $0.34,326.38$ \\
\hline
\end{tabular}

"Confidence Interval (CI) that does not include 1.00, significant

$B M I$ body mass index, GDM gestational diabetes mellitus, FIDs Fijians of Indian Descent

$\S$ others means part-Europeans, Chinese, and other Pacific Islanders

neonatal hypoglycaemia that should be considered when interpreting the results. Despite these limitations, the high prevalence of key neonatal outcomes of macrosomia and hypoglycaemia, may not have been different in this study, since previous studies have reported similar worse outcomes among women with GDM who were under strict glycaemic control [32, 35]. Similar to some studies [11, 62], we used the modified IADPSG criteria since the $1 \mathrm{~h}$ glucose was not available, which may have underestimated the odd ratios as more women with GDM could have been diagnosed using a $1 \mathrm{~h}$ blood glucose test compared to the 2- $\mathrm{h}$ glucose test (36\% versus 13\%) [63]. To be able to assess the impact of the IADPSG criteria in our setting, future studies should compare the maternal and fetal outcomes of women with GDM who were diagnosed using a $1 \mathrm{~h}$ blood glucose test and those diagnosed using the 2-h glucose test, to provide an opportunity for assessment of the cost effectiveness of both approaches.

This study has some strengths including inclusion of other clinical variables in the multivariable analysis, providing baseline information with which the ongoing universal testing can be assessed and allow endorsement of awareness campaigns to provide more knowledge on the adverse effects of GDM on neonates. The maternal socio-demographic characteristics as well as factors identified in this study can be used to develop future interventions to optimize maternal and infant health outcomes among Fijian women with GDM. The findings alert the health care providers on the high rate of macrosomia, hypoglycaemia and low Apgar Score in an urban Fiji population, and can alert Fijian women of their increased risk of adverse neonatal outcomes. While there are no published hyperglycaemia in pregnancy data from Fiji, this study showed worse birth outcomes compared to our earlier work (1994-1998) among Polynesians (including Fijians) and Europeans in South Auckland, New Zealand [35] which may be attributed to the anthropomorphic effects of the Fijian population. Given that $80 \%$ of births in the Central Eastern division occur in CWM hospital, it is likely that these findings may represent the Central Eastern division population.

\section{Conclusions}

This study has shown that offsprings of Fijian women with GDM have serious negative outcomes specifically macrosomia, hypoglycaemia and Apgar score. The risk increases among overweight/obese women, women with a previous baby weighing $>4 \mathrm{~kg}$, had delivered pre-term babies, had pre-eclampsia and those who booked later than 13 weeks in gestation. These factors should be taken into account when preventive intervention strategies are developed to improve outcomes and the target risk group is established. The high incidence of complications reported in this paper is clear evidence of the burden of GDM. Public enlightenment campaigns promoting booking in the first trimester among women with GDM and effective lifestyle interventions to prevent excessive weight gain in pregnancy are needed to improve the outcomes of pregnancies with GDM in the short term, and to reduce the long-term risk of type 2 diabetes for both mothers and their children. 


\section{Abbreviations}

AOR: Adjusted odds ratio; CWMH: Colonial War Memorial Hospital; DIP: Diabetes in pregnancy; GDM: Gestational diabetes mellitus; IADPSG: International Association of Diabetes and Pregnancy Study Groups; WHO: World Health Organization

\section{Acknowledgements}

The authors are grateful to Ms. Nola Mahe, Ilisapeci Kubuabola, Drs Julia Singh, Amanda Noovao, Pushpa Nusair, Litia Narube, Dr. Viliame Nasila, and Dr. Vasiti Cati for their guidance and continuous support during data collection.

\section{Authors' contributions}

FF obtained the data, conceptualized the study, and contributed to drafting the initial manuscript and critical revision of the manuscript. UO conceptualized the study, drafted the initial manuscript, analysis and interpretation of data and critical revision of the manuscript. KA conceptualized the study, analysed the data and contributed to drafting the initial manuscript and critical revision of the manuscript. GR conceptualized the original study design, participated in data collection and critical revision of the initial manuscript. NS participated in data collection, contributed to the conceptualized study and critically revised the initial manuscript. FJ partcipated in onceptualizing the study, interpreted the data and supervised data collection of the original study. DS interpreted the data, contributed to drafting the initial manuscript and critically revised the manuscript. All authors read and approved the final manuscript as submitted.

\section{Funding}

This study received no specific grant from any funding agency in the public, commercial or not-for-profit sectors.

\section{Availability of data and materials}

The datasets generated and analyzed during the current study are not publicly available due to the hospital policy but are available from the corresponding author on reasonable request.

\section{Ethics approval and consent to participate}

Permission to use the data set was obtained and the study was approved by the Ethics Committee of the College of Medical Nursing and Health Sciences of the Fiji National University and by the Fiji National Health Research Ethics Review Committees (ref \#: 2015.48.CEN). Only de-identified data was analysed in this study.

\section{Consent for publication}

Not applicable.

\section{Competing interests}

The authors declare that they have no competing interests.

\section{Author details}

${ }^{1}$ Ministry of Health, Vaoila Hospital, Nuku'alofa, Tongatapu, Tonga. ${ }^{2}$ Diabetes, Obesity and Metabolism Translational Research Unit (DOMTRU), School of Medicine, Western Sydney University, Campbelltown 2560, NSW, Australia. ${ }^{3}$ School of Health Sciences, Western Sydney University, Campbelltown 2560, NSW, Australia. ${ }^{4}$ African Vision Research Institute, University of KwaZulu-Natal Durban, Durban, South Africa. ${ }^{5}$ Department of Obstetrics and Gynaecology, Lautoka Hospital, Lautoka, Fiji. ${ }^{6}$ Department of Obstetrics and Gynecology, CWM Hospital, Suva, Fiji.

Received: 15 January 2019 Accepted: 18 February 2020

Published online: 28 February 2020

\section{References}

1. Nankervis A, Mclntyre H, Moses R, Ross G, Callaway L, Porter C, Jeffries W, Boorman C, De Vries B, AJMJ ME. ADIPS consensus guidelines for the testing and diagnosis of gestational diabetes mellitus in Australia; 2014.

2. Simmons D. Epidemiology of diabetes in pregnancy. A Practical Manual of Diabetes in Pregnancy. 2017;3:1-16.

3. Bellamy L, Casas JP, Hingorani AD, Williams D. Type 2 diabetes mellitus after gestational diabetes: a systematic review and meta-analysis. Lancet. 2009; 373(9677):1773-9.
4. Sellers EA, Dean HJ, Shafer LA, Martens PJ, Phillips-Beck W, Heaman M, Prior $\mathrm{HJ}$, Dart AB, McGavock J, Morris M, et al. Exposure to gestational diabetes mellitus: impact on the development of early-onset type 2 diabetes in Canadian first nations and non-first nations offspring. Diabetes Care. 2016; 39(12):2240-6.

5. Dabelea D, Mayer-Davis EJ, Lamichhane AP, D'Agostino RB Jr, Liese AD, Vehik KS, Narayan KM, Zeitler P, Hamman RF. Association of intrauterine exposure to maternal diabetes and obesity with type 2 diabetes in youth: the SEARCH case-control study. Diabetes Care. 2008;31(7):1422-6.

6. Crowther CA, Hiller JE, Moss JR, McPhee AJ, Jeffries WS, Robinson JS. Effect of treatment of gestational diabetes mellitus on pregnancy outcomes. $\mathrm{N}$ Engl J Med. 2005;352(24):2477-86.

7. Landon MB, Spong CY, Thom E, Carpenter MW, Ramin SM, Casey B, Wapner RJ Varner MW, Rouse DJ, Thorp JM Jr. A multicenter, randomized trial of treatment for mild gestational diabetes. N Engl J Med. 2009;361(14):1339-48.

8. Ekoé JM, Rewers M, Williams R, Zimmet P. The epidemiology of diabetes mellitus. 2nd ed. Oxford: Wiley; 2008.

9. Yapa M, Simmons D. Screening for gestational diabetes mellitus in a multiethnic population in New Zealand. Diabetes Res Clin Pract. 2000:48(3):217-23.

10. Chang AL, Hurwitz E, Miyamura J, Kaneshiro B, Sentell T. Maternal risk factors and perinatal outcomes among pacific islander groups in Hawaii: a retrospective cohort study using statewide hospital data. BMC Pregnancy Childbirth. 2015;15:239.

11. Wong W. Gestational diabetes mellitus in five ethnic groups: a comparison of their clinical characteristics. Diabet Med. 2011;29(3):366-71.

12. Hedderson MM, Darbinian JA, Ferrara A. Disparities in the risk of gestational diabetes by race-ethnicity and country of birth. Paediatr Perinat Epidemiol. 2010:24(5):441-8.

13. Lin S, Tukana I, Linhart C, Morrell S, Taylor R, Vatucawaqa P, Magliano DJ, Zimmet $P$. Diabetes and obesity trends in Fiji over 30 years. J Diabetes. 2016;8(4):533-43.

14. Yessoufou A, Moutairou K. Maternal diabetes in pregnancy: early and longterm outcomes on the offspring and the concept of "metabolic memory". Exp Diabetes Res. 2011;2011:218598.

15. Win Tin ST, Lee CMY, Colagiuri R. A profile of diabetes in Pacific Island countries and territories. Diabetes Res Clin Pract. 2015;107(2):233-46.

16. Zimmet P, Taylor R, Ram P, King H, Sloman G, Raper LR, Hunt D. Prevalence of diabetes and impaired glucose tolerance in the biracial (Melanesian and Indian) population of Fiji: a rural-urban comparison. Am J Epidemiol. 1983; 118(5):673-88.

17. Gyaneshwar R, Ram P. The prevalence of gestational diabetes in Fiji. Fiji Med J. 1990;16:40.

18. Kessaram T, McKenzie J, Girin N, Roth A, Vivili P, Williams G, Hoy D. Noncommunicable diseases and risk factors in adult populations of several Pacific Islands: results from the WHO STEPwise approach to surveillance. Aust N Z J Public Health. 2015;39(4):336-43.

19. O'Sullivan E, Avalos G, O'Reilly M, Dennedy M, Gaffney G, Dunne F, Collaborators AD. Atlantic diabetes in pregnancy (DIP): the prevalence and outcomes of gestational diabetes mellitus using new diagnostic criteria. Diabetologia. 2011;54(7):1670-5.

20. Metzger BE, Lowe LP, Dyer AR, Trimble ER, Chaovarindr U, Coustan DR, Hadden DR, McCance DR, Hod M, McIntyre HD, et al. Hyperglycemia and adverse pregnancy outcomes. N Engl J Med. 2008:358(19):1991-2002.

21. Ekeroma AJ, Craig ED, Stewart AW, Manetll CD, Mitchell EA. Ethnicity and birth outcome: New Zealand trends 1980-2001: Part 3, pregnancy outcomes for Pacific women. Aust N Z J Obstet Gynaecol. 2004;44:541-4.

22. Shipley GP, Taylor DA, Tyagi A, Tiwari G, Redd AJ. Genetic structure among Fijian island populations. J Hum Genet. 2015;60(2):69-75.

23. Parry J. Pacific islanders pay heavy price for abandoning traditional diet. World Health Organization Bulletin of the World Health Organization. 2010; 88(7):484.

24. Acharya S, Tudravu J, Kado J, Fong J, Cikamatana L, Delai A, Tukana I, Cornelius M. Diabetes Management Guidelines. In. Third Edition: NCD Control, Ministry of Health, Government of Fiji. 2012. p. 1-45. Available at: http://apps.who.int/medicinedocs/documents/s21731en/s21731en.pdf

25. FBoS. In: Statistics FBo, editor. Fiji Statistics at a Glance. Suva, Fiji Island: Fiji Bureau of Statistics; 2017

26. Organization WH. The Fiji Islands health system review. Manila: WHO Regional Office for the Western Pacific; 2011

27. International Association of Diabetes and Pregnancy Study Groups Consensus Panel. International association of diabetes and pregnancy study 
groups recommendations on the diagnosis and classification of hyperglycemia in pregnancy. Diabetes Care. 2010;33(3):676-82.

28. Wheaton P. Geoff Cumming: understanding the new statistics: effect sizes, confidence intervals and meta-analysis. Australas Phys Eng Sci Med. 2012; 35(4):511-2

29. Cordero L, Treuer SH, Landon MB, Gabbe SG. Management of infants of diabetic mothers. Arch Pediatr Adolesc Med. 1998;152(3):249-54.

30. King $\mathrm{H}$. Epidemiology of glucose intolerance and gestational diabetes in women of childbearing age. Diabetes Care. 1998;21(Suppl 2):B9-13.

31. Egan AM, Vellinga A, Harreiter J, Simmons D, Desoye G, Corcoy R, Adelantado JM, Devlieger R, Van Assche A, Galjaard S, et al. Epidemiology of gestational diabetes mellitus according to IADPSG/WHO 2013 criteria among obese pregnant women in Europe. Diabetologia. 2017;60(10):191321.

32. Simmons D. Relationship between maternal glycaemia and birth weight in glucose-tolerant women from different ethnic groups in New Zealand. Diabet Med. 2007;24(3):240-4

33. Organization WH. The Asia-Pacific perspective: redefining obesity and its treatment. Sydney: Health Communications Australia; 2000.

34. Blencowe $H$, Cousens $S$, Oestergaard MZ, Chou D, Moller A-B, Narwal R, Adler A, Garcia CV, Rohde S, Say L. National, regional, and worldwide estimates of preterm birth rates in the year 2010 with time trends since 1990 for selected countries: a systematic analysis and implications. Lancet. 2012;379(9832):2162-72.

35. Simmons D, Thompson CF, Conroy C. Incidence and risk factors for neonatal hypoglycaemia among women with gestational diabetes mellitus in South Auckland. Diabet Med. 2000;17(12):830-4.

36. Tsitas M, Schmid BC, Oehler MK, Tempfer CB. Macrosomic and low birth weight neonates in Pacific islanders from Samoa: a case-control study. Arch Gynecol Obstet. 2015;292(6):1261-6.

37. Rao AK, Daniels K, El-Sayed YY, Moshesh MK, Caughey AB. Perinatal outcomes among Asian American and Pacific islander women. Am J Obstet Gynecol. 2006;195(3):834-8.

38. Silva JK, Kaholokula JK, Ratner R, Mau M. Ethnic differences in perinata outcome of gestational diabetes mellitus. Diabetes Care. 2006;29(9):2058-63.

39. Kc K, Shakya S, Zhang H. Gestational Diabetes Mellitus and Macrosomia: A Literature Review. Ann Nutr Metab. 2015;66(Suppl. 2):14-20.

40. Langer O, Yogev Y, Most O, Xenakis EM. Gestational diabetes: the consequences of not treating. Am J Obstet Gynecol. 2005;192(4):989-97.

41. Langer O, Levy J, Brustman L, Anyaegbunam A, Merkatz R, Divon M. Glycemic control in gestational diabetes mellitus-how tight is tight enough: small for gestational age versus large for gestational age? Am J Obstet Gynecol. 1989;161(3):646-53.

42. Said AS, Manji KP. Risk factors and outcomes of fetal macrosomia in a tertiary Centre in Tanzania: a case-control study. BMC Pregnancy and Childbirth. 2016;16(1):243.

43. Boulet SL, Alexander GR, Salihu HM, Pass M. Macrosomic births in the United States: determinants, outcomes, and proposed grades of risk. Am J Obstet Gynecol. 2003;188(5):1372-8.

44. Catalano PM, Thomas A, Huston-Presley L, Amini SB. Increased fetal adiposity: a very sensitive marker of abnormal in utero development. Am J Obstet Gynecol. 2003;189(6):1698-704.

45. Clausen TD, Mathiesen E, Ekbom P, Hellmuth E, Mandrup-Poulsen T, Damm P. Poor pregnancy outcome in women with type 2 diabetes. Diabetes Care. 2005;28(2):323.

46. Schaefer-Graf UM, Kjos SL, Kilavuz Ö, Plagemann A, Brauer M, Dudenhausen $\mathrm{JW}$, Vetter K. Determinants of fetal growth at different periods of pregnancies complicated by gestational diabetes mellitus or impaired glucose tolerance. Diabetes Care. 2003;26(1):193.

47. Pedersen J, Bojsen-Møller B, Poulsen H. Blood sugar in newborn infants of diabetic mothers. Acta Endocrinol. 1954;15(1):33-52.

48. Poon LC, Karagiannis G, Stratieva V, Syngelaki A, Nicolaides KH. Firsttrimester prediction of macrosomia. Fetal Diagnosis Therapy. 2011;29(2): 139-47.

49. Migda M, Migda M, Migda B, Wender-Ozegowska EJ. Maternal first trimester parameters in the prediction of excessive fetal growth in pregnant women with metabolic syndrome. J Physiol Pharmacol. 2017;68:833-9.

50. Saunders DL, Makutu SL. Cesarean section deliveries in Fiji, 1986 to 1996. Pacific health dialog. 2001;8(1):71-7.

51. García-Patterson A, Aulinas A, María MÁ, Úbeda J, Orellana I, Ginovart G, Adelantado JM, de Leiva A, Corcoy R. Maternal body mass index is a predictor of neonatal hypoglycemia in gestational diabetes mellitus. J Clin Endocrinol Metab. 2012;97(5):1623-8.

52. WHO. Noncommunicable diseases in the Western Pacific Region: a profile. Manila: WHO Regional Office for the Western Pacific; 2012.

53. Yamamoto JM, Kellett JE, Balsells M, Garcia-Patterson A, Hadar E, Sola I, Gich I, van der Beek EM, Castaneda-Gutierrez E, Heinonen S, et al. Gestational diabetes mellitus and diet: a systematic review and meta-analysis of randomized controlled trials examining the impact of modified dietary interventions on maternal glucose control and neonatal birth weight. Diabetes Care. 2018;41(7):1346-61.

54. Hedderson MM, Ferrara AA, Sacks AD. Gestational diabetes mellitus and lesser degrees of pregnancy hyperglycemia: association with increased risk of spontaneous preterm birth. Obstet Gynecol. 2003;102(4):850-6.

55. Voormolen DN, de Wit L, van Rijn BB, DeVries JH, Heringa MP, Franx A, Groenendaal F, Lamain-de Ruiter M. Neonatal hypoglycemia following dietcontrolled and insulin-treated gestational diabetes mellitus. Diabetes Care. 2018;41(7):1385.

56. Schaefer-Graf UM, Rossi R, Bührer C, Siebert G, Kjos SL, Dudenhausen JW, Vetter K. Rate and risk factors of hypoglycemia in large-for-gestational-age newborn infants of nondiabetic mothers. Am J Obstet Gynecol. 2002;187(4): 913-7.

57. Group HSCR. Hyperglycemia and adverse pregnancy outcomes. N Engl J Med. 2008;358(19):1991-2002.

58. Nliodromiti S, Mackay DF, Smith GCS, Pell JP, Nelson SM. Apgar score and the risk of cause-specific infant mortality: a population-based cohort study. Lancet. 2014;384(9956):1749-55.

59. Bythell M, Nand D, Tikoduadua L, Vereti I, Kado J, Fong J, Jenkins K. K M: stillbirths, neonatal and infant mortality in Fiji 2012: preliminary findings of a review of medical cause of death certificates. Ministry of Health and Medical Services: Fiji Journal of Public Health; 2016.

60. Simmons D, Nema J, Parton C, Vizza L, Robertson A, Rajagopal R, Ussher J, Perz J. The treatment of booking gestational diabetes mellitus (TOBOGM) pilot randomised controlled trial. BMC pregnancy and childbirth. 2018;18(1): 151.

61. van Leeuwen M, Louwerse MD, Opmeer BC, Limpens J, Serlie MJ, Reitsma JB, Mol BWJ. Glucose challenge test for detecting gestational diabetes mellitus: a systematic review. Int J Obstet Gynaecol. 2012;119(4):393-401.

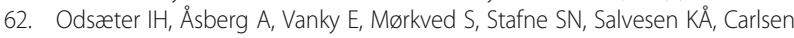
SM. Hemoglobin A1C as screening for gestational diabetes mellitus in Nordic Caucasian women. Diabetol Metab Syndr. 2016;8(1):43.

63. Metzger BE, Gabbe SG, Persson B, Buchanan TA, Catalano PA, Damm P, Dyer AR, Leiva A, Hod M, Kitzmiler JL, et al. International association of diabetes and pregnancy study groups recommendations on the diagnosis and classification of hyperglycemia in pregnancy. Diabetes Care. 2010;33(3):676-82.

\section{Publisher's Note}

Springer Nature remains neutral with regard to jurisdictional claims in published maps and institutional affiliations.
Ready to submit your research? Choose BMC and benefit from:

- fast, convenient online submission

- thorough peer review by experienced researchers in your field

- rapid publication on acceptance

- support for research data, including large and complex data types

- gold Open Access which fosters wider collaboration and increased citations

- maximum visibility for your research: over $100 \mathrm{M}$ website views per year

At $\mathrm{BMC}$, research is always in progress.

Learn more biomedcentral.com/submissions 